\title{
Design of Fuzzi-Pid Tracking Controller for Industrial Conveyor System
}

\author{
Chimezirim O. A, Lazarus O.U, Olubiwe M, Okozi S.O \\ Department of Electrical and Electronic Engineering, \\ Federal University of Technology, Owerri, \\ Imo state, Nigeria.
}

\begin{abstract}
In recent times, the importance of belt conveyor system, especially in industrial products such as cars, audio and video devices, computer devices etc., cannot be over emphasized. Belt conveyor systems are fast becoming one of the fastest means of transporting loads/products with maximum reliability and accuracy in our industries In industrial processes, a conveyor is required to move products/materials from one position to another point where the conveyor stops for machines placed at these points to process the material/product for onward movement to the next machine until the process is complete. However these products are not properly positioned at times, leading to spills, industrial accident and production of defective products. The study was achieved through the following methodology; Obtaining the mathematical model of the conveyor system, Controllability test of the conveyor system model, PID controller design, Stability analysis of the conveyor system with PID controller, Simulation and validating the model. The results showed that the control parameters obtained have: a settling time of 0.835 seconds, the rise time of 0.062 seconds, the percentage overshoot of $4.8 \%$ and no steady-state error. The reduced settling time of 0.835 seconds indicates a faster timing and adaptability of system to additional load. The rise time of 0.062 seconds and small overshoot of $4.8 \%$ further confirm optimization effect of the PID controller on the system. A steady - state error of $0 \%$ shows improved system stability. The control parameters obtained in fuzzy - PID system has a settling time of 0.463 seconds, the rise time of 0.081 seconds, the percentage overshoot of $2.4 \%$ and no steady-state error. The settling time, rise time and percentage overshoot indicates a faster and better tracking performance of the system. This shows the optimization effect of the Fuzzy-PID controller on the conveyor system. The steady-state error which is $0 \%$ shows improved system stability. The study achieved the set objective by enhancing a better way of industrial conveyor system control.
\end{abstract}

Key Words: Fuzzy, Industrial, conveyor, PID, Controllability, Mathematical model

\section{INTRODUCTION}

In industrial processes, a conveyor is required to move products/materials from one position to another point where the conveyor stops for machines placed at these points to process the material/product for onward movement to the next machine until the process is complete. However these products are not properly positioned at times leading to spills, industrial accident and production of defective products, hence a control system is required. In recent times, the importance of belt conveyor system, especially in industrial products such as cars, audio and video devices, computer devices etc., cannot be over emphasized. Belt conveyor systems are fast becoming one of the fastest means of transporting loads/products with maximum reliability and accuracy in our industries. In many process or manufacturing industrial environments, belt conveyor systems have been identified as reliable tools for lifting or transporting bulk materials or products (loads) from one point to another depending on the speed of handling, height of transportation, nature, quantity, size and weight of materials to be transported. This study is geared towards designing of a scheme to increase the positioning performance of typical industrial Belt conveyor systems A belt is a looped strip of flexible material used to mechanically link two or more rotating shafts, most often parallel. Belts are looped over pulleys and may have a twist between the pulleys, and the shafts need not be parallel . A belt can either drive the pulleys normally in one direction or the belt may be crossed, so that the direction of the driven shaft is reversed in a two pulley system. When used as a source of motion, a belt drive is one application where the belt is adapted to continuously carry a load between two points.[1] Belt drives are used as the source of motion to efficiently transmit power or to track relative movement. Belt drives are widely applied in different fields of human activity to transmit the mechanical energy from the rotating shaft to the objects of the control Using belt drives for high precision applications has become appropriate because of rapid development of motor and drive technology as well as the implementation of timing belts in belt-driven systems [2]. The use of belts in drives has brought about a number of advantages. Systems can provide high speed and acceleration, accurate and repeatable motion, high efficiency, long stroke lengths and low cost [3]. In modern times Direct Current (DC) motors are being widely used in many belt drive systems due to precise, wide, simple and continuous control characteristics. High performance DC motor belt drives are very important in both industrial and other applications. Good dynamic speed command tracking and load regulating response is generally one of the main characteristics of high performance motor drive system. As a rule of thumb, belt drives use either the speed controlled drives if the rotation of control object is needed or the servo drives if the position control is required [2]. An electrical servo system includes four main parts: a servomotor, a power converter, sensors and a load. Modern closed-loop control systems allow the servo drives to achieve high dynamic performance with high efficiency. 
The modern servo systems are characterized by the strong requirements for the next important properties: positioning accuracy, speed accuracy, torque stability, overload capability and dynamic performance [4].

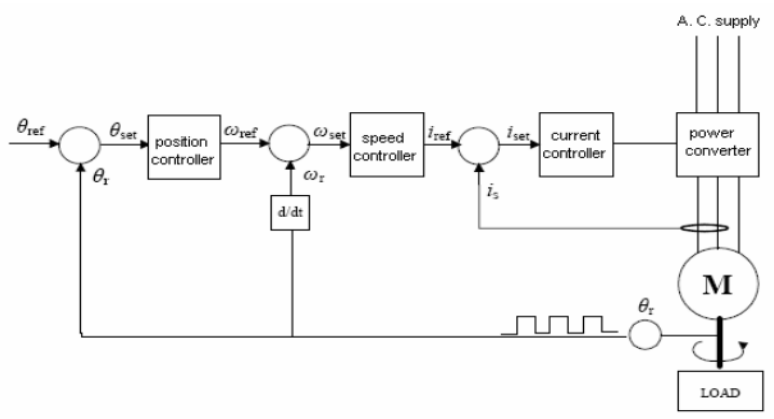

Fig 1: Typical servo control structure based on cascade principle [2]

Different position control methods such as fork lifting, use of bucket elevators, conveyors systems, crane, etc. have been identified for lifting or transporting bulk materials or products from one place to another in the process or manufacturing industries depending on the speed of handling, height of transportation, nature, quantity, size and weight of materials to be transported. One of the major industrial applications of belt-driven systems is found in industrial conveyor systems. A typical conveyor system consists of conveyor belt, pulleys and idlers, coupling, bearing, DC drive motor, pneumatic cylinder, structural frame and hopper. Couplings are the devices used to couple or connect two shafts and this is one of the most important components of any drive system. A hopper is used to transferring materials or load from one conveyor belt to other and helps to avoid the spillage of material. A pneumatic cylinder is a device with two chambers separated by a bore, with each chamber having one valve and each valve having two ports or orifices [5]. There are many types of conveyor systems available based on different principles of operation and various needs of different industries. These includes: Belt conveyors, Gravity conveyor, Gravity skate wheel conveyor, Wire mesh conveyors, Plastic belt conveyors, Bucket conveyors, Flexible conveyors, Vertical conveyors, Spiral conveyors, Vibrating conveyors, Pneumatic conveyors, Electric track vehicle systems, Belt driven live roller conveyors, Line shaft roller conveyor, Chain conveyor, Screw conveyor or auger conveyor, Chain driven live roller conveyor, Overhead I-beam conveyors, Dust proof conveyors, Automotive conveyors, Overland conveyor, Drag Conveyor etc. The choice of a particular conveyor system however depends on the load to be transported, speed of transportation, size and weight of the load to be transported, height or distance of transportation, nature of material, and method of production employed [1].

\section{PREVIOUS WORKS REVIEWED}

[6] worked on modelling and PID controller system synthesis for belt conveyor system using polynomial stabilization method which computationally characterizes the entire set of admissible PID gains for various control system configurations. The paper also showed that a correction was needed in order to find all robust PID region controllers that satisfy a given robust performance. The work also provided a selection procedure for searching the best PID gains controllers in the obtained PID gains region. The paper later applied the correct polynomial stabilization algorithm on a short D.C servo- driven belt conveyor system. A research work by [7] investigated the dynamic starting behaviour of long multiple drive belt conveyors. The paper made a comparison between the starting behaviour of a single and a multiple drive layout with no load on the belt by simulating a speed controlled start procedure with a dynamic model. The work also compared the previous simulation with simulation of a multiple drive layout that was configured for a loaded belt. Result of the study showed that a link can be established between dynamic behaviour of the belt sections in a multiple drive belt conveyor system and a single drive conveyor system. The work used Enerka-Berker system as test case due to its multiple drive layout and light belt construction.

[8] described a belt conveyor as a transportation of material from one location to another. Belt conveyor has high load carrying capacity, large length of conveying path, simple design, easy maintenance and high reliability of operation. Belt conveyor system is also used in material transport in foundry shop like supply and distribution of moulding sand, moulds and removal of waste. In the paper, a study was carried out on Defence Information Systems Agency (DISA) pattern moulding machine to meet the requirement of higher weight castings. The DISA machine was having the capacity of 100 moulds per hour. The mould size and density of material was given parameters. The present discussion aimed at designing the conveyor system used for cooling of mould, which includes speed, motor selection, belt specification, shaft diameter, pulley, idler spacing, gear box selection, with the help of standard practice and these results were verified with the belt computer software. [9] stated that belt conveyors are a dominant means of transportation in modern open-pit mines in Bosnia and Herzegovina. They were usually driven by three-phase induction slip-ring motors of a nominal voltage of $6 \mathrm{kV}$ and nominal power from 200 to $1000 \mathrm{~kW}$. Efficiency of the transport system was the crucial parameter of the level of economical exploitation of an open-pit mine as a whole. The main problem which prevents optimal transport system efficiency was insufficient synchronization between the production and transport capacities. Since the conveyors in the open-pit mines in Bosnia and Herzegovina were mainly driven by three-phase induction slip-ring motors, the most appropriate solution to control the conveyor speed (the speed of the drive motors) was to use a subsynchronous constant torque cascade with a static voltage and frequency converter. The basic elements of the subsynchronous cascade were a diode bridge rectifier and a thyristor inverter bridge, as well as a power transformer whose nominal power depends on the control range and which sends electricity back to the power grid. The paper described a mathematical model to calculate the subsynchronous cascade parameters used in controlling the 
speed of electric-motor drives for belt conveyors. [10] presented a paper on the knowledge of damage process which was required for the correct regulation of operating conditions for conveyor belt. The aim was to determine conditions under which these damages occur (height of impact and weight of material impact). The current trend was to provide weight/cost effective products which met the stringent requirements. The aim of the paper was to study existing conveyor system and optimize the Belt speed, Width, Wrapping angle, Pulley diameter and addition of Snub pulley. [11] presented the mathematical model of a conveyor mechanism for control applications with champion breweries PLC as a case study. In the work, the electrical and mechanical sections were modelled separately and then integrated to obtain one composite system. The paper designed a proportional integral derivative controller to act as a speed synchroniser in order to eliminate the problem of non-synchronization. The result of the study showed that an improvement in system response when PID speed synchroniser was coupled with the feedback loop. Selezneva (2007) studied the use of belt for high precision applications that became appropriate because of the rapid development in motor and drive technology as well as the implementation of timing belts in servo systems. Belt drive systems provide high speed and acceleration, accurate and repeatable motion with high efficiency, long stroke lengths and low cost. Modelling of a linear belt-drive system and designing its position control were examined in the research work. Friction phenomena and position dependent elasticity of the belt were analyzed. Computer simulated results showed that the developed model was adequate. The PID control for accurate tracking control and accurate position control was designed and applied to the real test setup. Both the simulation and the experimental results demonstrated that specifications. The designed controller met the specified performance specifications.

[12] described a conveyor belt to include at least one rip detection sensor, one position detection sensor and a speed measurement sensor. In the paper a complete sensor solution for the industrial conveyer belt was given. The intelligent sensors were discovered to have one master intelligent sensor and number of slave sensors depending upon the length of the belt. The intelligent sensor system not only increased the life of the conveyer belt but also increased overall efficiency of the system and it also reduced the processing overhead of the final unit since most of the processing was done in this sensor set by the intelligent master sensor herby increasing not only the belt life but as well as it extended the sensor life as the conveyor belt wears.

The work by [13] developed a controller scheme for a sorting machine which was made up of conveyor belt and a skid both attached to a D.C motor and a photo detector. The sorting machine in the work was required to sort sticks of different lengths into a predestined bucket while keeping statistics on how many sticks are sorted and also keep track of how many odd sticks ( too long or too short) are passing through the machine and where they went. The work used two controllers for the conveyor belt and skid; the skid controller was designed with PD controller whereas the conveyor belt was designed with PI controller. Furthermore, the study developed a physical model of two D.C motors, designed two controllers in MATLAB using frequency response method and implemented it on real time system. The system designed in the work was able to sort sticks reliably up to a speed of $1.0 \mathrm{~m} / \mathrm{s}$ with a minimum gap of $2.0 \mathrm{~mm}$.

The various sections of the literature review so far reveals the fact that extensive research has been carried out over the years on the many different aspects of the design or modelling, experiments and simulations of belt conveyor systems. The reviews of previous research was carried out in a general-to-specific pattern. This exposed a good number of significant innovative improvement made in the past on conveyor systems.

Nevertheless, the above review of previous research work and various advancements on conveyor systems revealed the strengths and weaknesses of these technologies. Also, it extensively shows the level of achievement made by previous researchers so far in the field of industrial belt conveyor systems. Most relevant of the reviews are the lingering challenge of wrong positioning and poor efficiency of industrial belt conveyor systems which are not advanced enough to fully meet the current industrial standards.

\section{MATHEMATICAL MODEL OF BELT CONVEYOR SYSTEMS}

The mathematical models suitable for optimization of a typical belt conveyor systems are presented in this section. The model presented below is a combination of equations. The model made use of torque balance equation and was chosen after considering other models. Thus we have

$K_{m} i(t)-J \frac{d^{2} \theta}{d t^{2}}-B \frac{d \theta}{d t}(t)-M_{T} r \frac{d \theta}{d t}(t)-k r \theta(t)=0(1)$ Therefore

$K_{m} i(t)=J \frac{d^{2} \theta}{d t^{2}}+B \frac{d \theta}{d t}(t)+M_{T} r \frac{d \theta}{d t}+k r \theta$

Taking laplace transform we have

$K_{m} I(s)=J s^{2} \theta(s)+B s \theta(s)+M_{T} r s^{2} \theta(s)+\mathrm{kr} \theta(s)$

Also, $\mathrm{I}=\frac{V_{a p p(s)}-K_{b} s \theta(s)}{R(s) L S(s)}$

Substituting equation (4) into equation (3)

$$
\begin{aligned}
& \text { We have } K_{m} \frac{V_{a p p(s)}-K_{b} s \theta(s)}{R(s) L S(s)}= \\
& J s^{2} \theta(s)+B s \theta(s)+M_{T} s^{2} r \theta(s)+\mathrm{kr} \theta(s) \\
& \text { Therefore the overall transfer function is: } \\
& G_{P}(s)=\frac{\theta(s)}{V_{a p p(s)}}= \\
& \frac{K_{m}}{s(J s+B)(L s+R)+\left(M_{T} r s^{2}+k r\right)(L s+R)+k_{m} k_{b} s}
\end{aligned}
$$




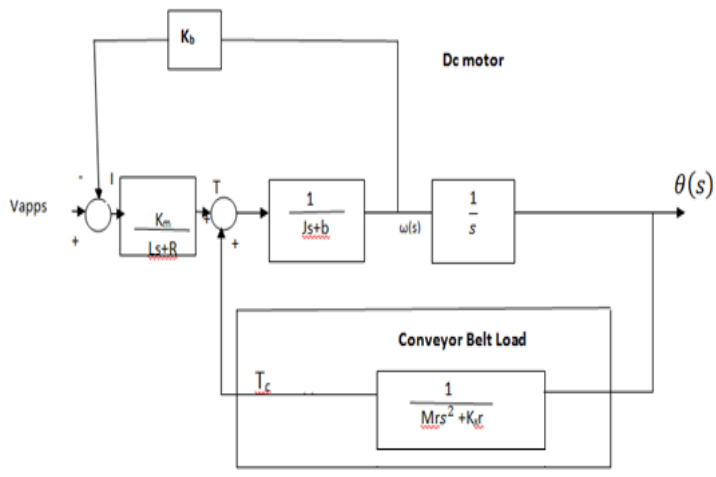

Fig. 2: Control Block diagram of the conveyor model

Where the parameters are as follows

$\mathrm{J}=1.2 \times 10^{-6} \mathrm{kgm}^{2}$

$K_{m}=13.3 \times 10^{-1} \mathrm{NM} / \mathrm{A}$

$K_{b}=13.33 \times 10^{-1} \mathrm{Volt} / \mathrm{rad}$

$R=2.17 \Omega$

$L=1.17 \times 10^{-2} \mathrm{H}$

$B=2.5 \times 10^{-3} \mathrm{Nms}$

$\mathrm{M}_{\mathrm{m}}=1.0 \mathrm{~kg}$

$\mathrm{M}_{\mathrm{b}}=0.2 \mathrm{~kg}$

$\mathrm{r}=17.4 \mathrm{~mm}=0.0174 \mathrm{~m}$

$M_{T}=1.2 \mathrm{Kg}$

$K=4.5 \times 10^{-2} N / M$

Substituting the values above into Equation (6) we have

$G_{P}(s)=\frac{\theta(s)}{V_{a p p(s)}}=$

$\frac{1.33}{0.0002443 s^{3}+45.34 s^{2}+1.774 s+0.001699}$

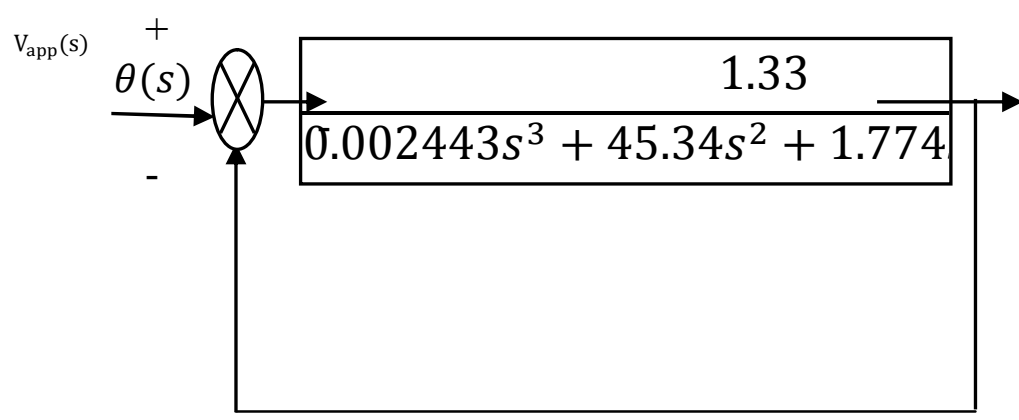

Fig. 3: Control Block Diagram of a Belt Conveyor System

\section{STATE SPACE REPRESENTATION OF CONVEYOR MODEL}

The state space representation of conveyor system model is used to determine the controllability of the system. The state equations of the conveyor system can be derived from Equation (7) (transfer function)

Let the output $\theta$ be $Y$ and the input voltage $\mathrm{V}_{\text {app }}$ be $\mathrm{U}$. The transfer function in Equation (7) can be written as

$\frac{Y}{U}=\frac{1.33}{0.0002443 s^{3}+0.04534 s^{2}+1.774 s+0.001699}(8)$

This implies that
$0.0002443 Y^{3}{ }^{3}+0.04534 Y^{2} s^{2}+1.774 Y s+0.001699 Y=$ $1.33 \mathrm{U}(\mathrm{s})$

Dividing through by 0.0002443 we have

$Y s^{3}+185.59 Y s^{2}+7261.56 Y s+6.95 Y=5444.12 U(s)$

Let $\mathrm{Y}=x_{1}$

$x_{1} s^{3}+185.59 x_{1} s^{2}+7261.56 x_{1} s+6.95 x_{1}=$

$5444.12 U(s)$

Taking the inverse Laplace transform of equation (10),

$\frac{d^{3} x_{1}}{d t^{3}}+185.59 \frac{d^{2} x_{1}}{d t^{2}}+7261.56 \frac{d x_{1}}{d t}+6.95 x_{1}=$

$5444.12 u(t)$

Equation (11) can be expressed in time domain as

$\dddot{x}_{1}+185.59 \ddot{x}_{1}+7261.56 \dot{x}_{1}+6.95 x_{1}=5444.12 u(t)$

(12)

$\dot{x}_{1}=x_{2}$

(13)

$\ddot{x}_{1}=\dot{x}_{2}=x_{3}$

(14)

$\dddot{x}_{1}=-185.59 x_{3}-7261.56 x_{2}-6.95 x_{1}+$

$5444.12 u(t)$

This implies that

$\dot{x}_{1}=x_{2}$

$\dot{x}_{2}=x_{3}$

(17)

$\dot{x}_{3}=-6.95 x_{1}-7261.56 x_{2}-185.59 x_{3}+5444.12 u(t)$

(18)

Bringing equations (16), (17) and 18() together describes the state equation

$$
\begin{aligned}
& {\left[\begin{array}{l}
\dot{x}_{1} \\
\dot{x}_{2} \\
\dot{x}_{3}
\end{array}\right]=\left[\begin{array}{ccc}
0 & 1 & 0 \\
0 & 0 & 1 \\
-6.95 & -7261.56 & -185.59
\end{array}\right]\left[\begin{array}{l}
x_{1} \\
x_{2} \\
x_{3}
\end{array}\right]+} \\
& {\left[\begin{array}{c}
0 \\
0 \\
5444.12
\end{array}\right] u(t)} \\
&
\end{aligned}
$$

The output of the state equation, $y=x_{1}$ can be written as $y=\left[\begin{array}{lll}1 & 0 & 0\end{array}\right]\left[\begin{array}{l}x_{1} \\ x_{2} \\ x_{3}\end{array}\right]$

\section{PID CONTROLLER DESIGN}

A suitable controller employed in industrial control systems for three-term control-loop feedback mechanism is the Proportional Integral Derivative (PID) controller. The PID controller minimizes system error by adjusting the process through the use of a manipulated variable. It ensures optimum control dynamics including zero steady state error, fast response (short rise time), reduced overshoot, no oscillations and higher stability. The use of PID controller in higher order processes is the main advantage it has over some other linear controllers. 


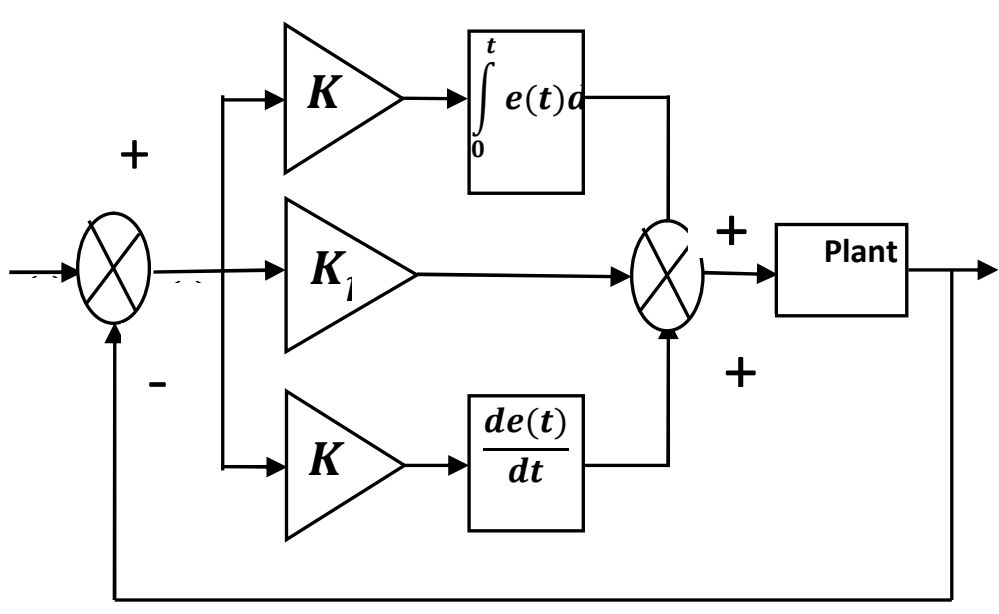

Fig 4: The Model of a PID Controller Configuration.

The overall mathematical description of linear relationship existing between the controller output, $\mathrm{u}(\mathrm{t})$ and the error, $\mathrm{e}(\mathrm{t})$ in Figure 4 is expressed as in Equation (21).

$u(t)=K_{p} e(t)+K_{i} \int e(t) d t+K_{d} \frac{d e(t)}{d t}$

Where $\mathrm{T}_{\mathrm{i}}=$ integral time and $\mathrm{T}_{\mathrm{d}}=$ derivative time. In Figure $4, \mathrm{~K}_{\mathrm{p}}=$ proportional gain, $\mathrm{K}_{\mathrm{i}}$ = integral gain, and $\mathrm{K}_{\mathrm{d}}$ $=$ derivative gain.

There are three separate constant parameters (Controller Gains) involved in PID controller algorithm namely: The proportional controller, $\mathrm{K}_{\mathrm{p}}$ there is a continuous relationship between the output of the controller (Controlled Variable) and the actuating error signal $\mathrm{e}(\mathrm{t})$ (deviation). Basically, proportional controller is an amplifier with adjustable gain. The action of this controller depends on the present error and it is used to decrease the steady state error of the system. The integral controller, $\mathrm{K}_{\mathrm{i}}$ (also known as Reset Control), changes at a rate proportional to the actuating accumulation of past error signal $\mathrm{e}(\mathrm{t})$. In a typical derivative control action, the output of the controller depends on the rate of change of the actuating prediction of future error signal $\mathrm{e}(\mathrm{t})$. This type of controller cannot be used alone because when the error is zero or constant, the output of the controller will be zero.

Applying the PID controller to any control system involves adjusting the values of gain $K_{p}, K_{i}$ and $K_{d}$ in order to obtain the best response of the system. The selection of PID controller gain values causes the variation of observed response with respect to desired response.

\section{A Conveyor System Closed-Loop Control Model}

The overall conveyor system model with PID controller is shown in figure 5

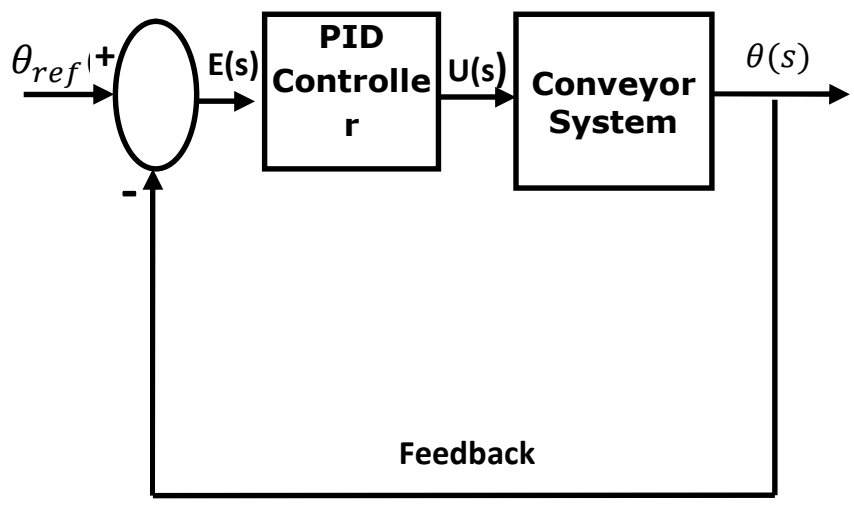

Fig. 5: Block Diagram of a Conveyor Control System.

In Figure 5, the conveyor control system block consists of PID controller and a conveyor system model transfer function. The input to the conveyor system model is the controlled voltage from the PID controller. This voltage determines the behaviour of the belt conveyor system.

The SIMULINK representation of Figure 5 is shown in figure 6 .

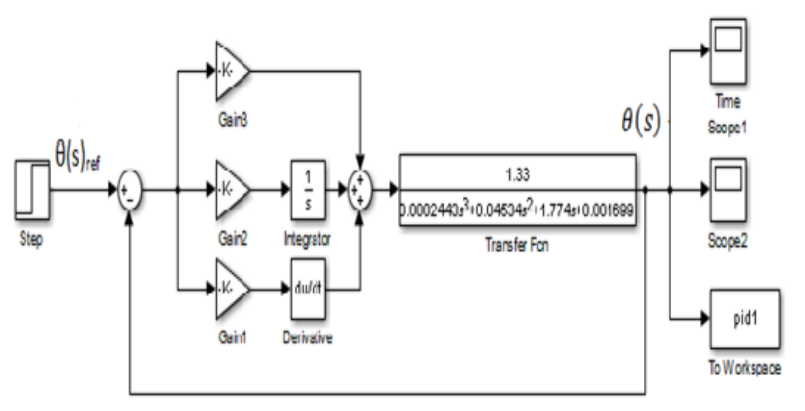

Fig. 6: Belt Conveyor Closed-loop Control System Simulink Model.

The actual PID controller gains in figure 6 are $K_{p}=$ 94.6893, $K_{i}=132.7941$ and $K_{d}=2.6315$. Putting these controller gains obtained from the tuning into a standard controller equation gives equation (22)

$G_{c}(s)=94.6893+132.7941 \frac{1}{s}+2.6315 \mathrm{~s}$

The overall equation of the belt conveyor control system forward path in Figure 6 is given by the combining equation 7 and 22 as shown in Equation 23 below.

$$
\begin{aligned}
& G_{\text {overall }}(s)=G_{C}(s) * G(s) \\
& =\left(94.6893+132.7941 \frac{1}{s}+2.6315 \mathrm{~s}\right. \\
& \frac{1.33}{0.0002443 \mathrm{~S}^{3}+0.04534 \mathrm{~S}^{2}+1.774 \mathrm{~s}+0.001699} \\
& =\frac{3.5 S^{2}+125.9 S+176.6}{0.0002443 s^{4}+0.04534 s^{3}+1.774 s^{2}+0.001699 s}
\end{aligned}
$$


The closed-loop transfer function of the belt conveyor control system can be derived as follow:

$$
\begin{aligned}
& G_{\text {cloop }}(s)=\frac{G_{\text {overall }}(s)}{1+G_{\text {overall }}(s)} \\
& \quad=\frac{3.5 S^{2}+125.9 S+176.6}{0.0002443 s^{4}+0.04534 s^{3}+5.274 s^{2}+125.90 s+176.6}
\end{aligned}
$$

\section{DESIGN OF FUZZY PID CONTROLLER}

The Fuzzy-PID Controller is a combination of Fuzzy Logic Controller and PID Controller. The table below shows the fuzzy rules table used in the Fuzzy-PID Controller. There are 25 fuzzy rules used for the Fuzzy-PID Controller.

\begin{tabular}{|c|c|c|c|c|c|}
\hline T/Ae & NB & NS & ZE & PS & PB \\
\hline NB & NB & NB & NM & NS & ZE \\
\hline NS & NB & NM & NS & ZE & PS \\
\hline ZE & NM & NS & ZE & PS & PM \\
\hline PS & NS & ZE & PS & PB & PB \\
\hline PB & ZE & PS & PM & PB & PB \\
\hline
\end{tabular}

The membership functions for error (e), change in error(ec) and output are shown in Figure 7, 8 and 9.

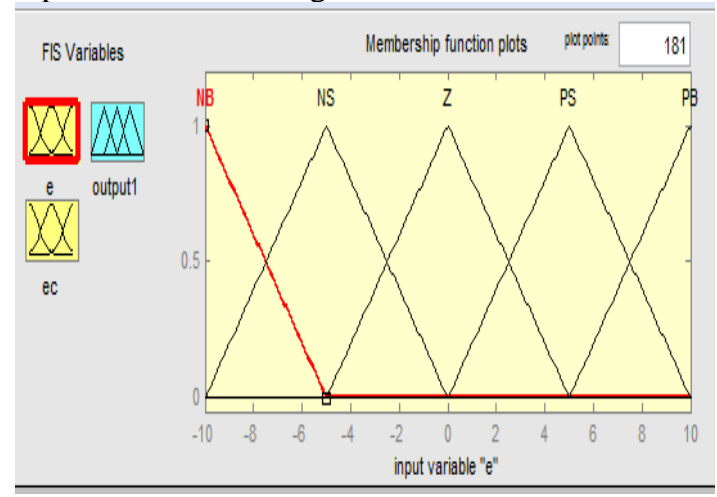

Fig. 7: Membership function for error

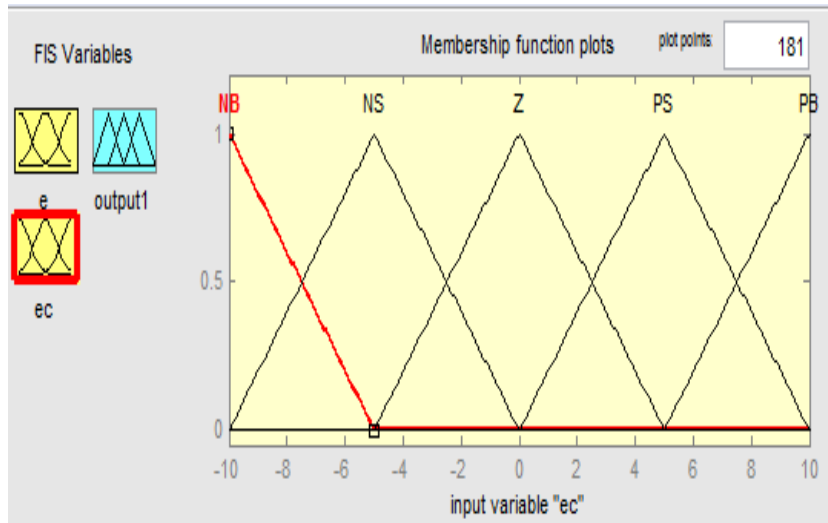

Fig. 8: Membership function for change in error (ce)

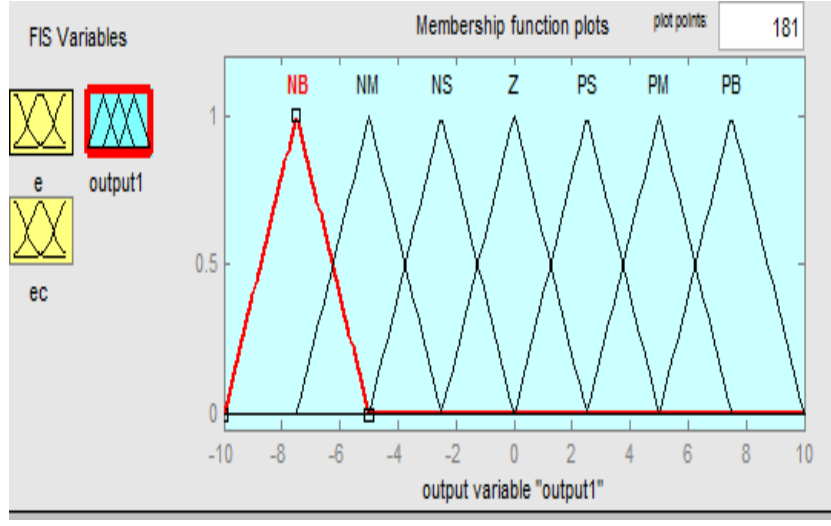

Fig. 9: Membership function for output

From the figures 7-9 above, it can be seen that output have two more membership function than the inputs.

The simulink diagram for the Fuzzy-PID Controller is as shown in Figure 10

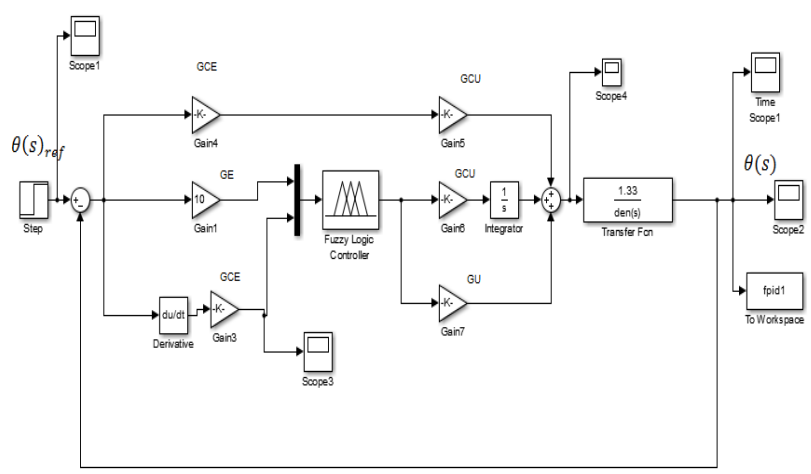

Fig. 10: Simulink model Conveyor system with Fuzzy-PID Controller

The gains of the Fuzzy-PID Controller were calculated from PID gains as shown below.

$\mathrm{K}=94.69$;

$\mathrm{Ki}=132.79$;

$\mathrm{kd}=2.63$;

$\mathrm{GE}=$ input range $=10$

$\mathrm{GCE}=G E \times\left(k p-\left(\sqrt{k p^{2}}-4 k i k d\right)\right) \div \frac{2}{k i}=0.2895$

(25)

$$
\begin{aligned}
& \mathrm{GCU}=k i / G E=13.279 \\
& \mathrm{GU}=k d /{ }_{G C E}=9.0846
\end{aligned}
$$

\section{STABILITY TEST}

The overall simulation result (closed-loop transfer function) of the conveyor system in Equation (24) can be verified for stability using Routh-Hurwitz Criterion. From equation (24), the characteristic equation becomes

$1+\mathrm{G}_{\mathrm{P}} \mathrm{G}_{\mathrm{C}}=0$

$0.0002443 s^{4}+0.04534 s^{3}+5.274 s^{2}+125.9 s+$

$176.6=0$

Equation (28) can be represented as $a_{0} s^{4}+a_{1} s^{3}+a_{2} s^{2}+a_{3} s+a_{4}=0$

(29) 
The coefficients in equation (29), $a_{0}, a_{1}, a_{2}, a_{3}$ and $a_{4}$ are all the same sign and none zero. The coefficients of Equation (29) can be arranged in the format in Equation (30).

$\begin{array}{llll}s^{4} & a_{0} & a_{2} & a_{4} \\ s^{3} & a_{1} & a_{3} & a_{5} \\ s^{2} & b_{1} & b_{2} & b_{3} \\ s^{1} & c_{1} & c_{2} & c_{3} \\ s^{0} & d_{1} & d_{2} & d_{3}\end{array}$

(30)

The Routh-Hurwitz Criterion states that the number of roots with positive real parts is equal to the number of changes in sign of the first column of the Routh array. The criterion implies that a system is stable if and only if all the elements (coefficients) in the first column have the same algebraic sign.

Comparing equation (28) and (29), $a_{0}=$ $0.0002443, a_{1}=0.04534, a_{2}=5.274, a_{3}=125.9$

and $a_{4}=176.6$. The other coefficients in equation (29) can be computed as follows:

$b_{1}=-\frac{1}{a_{1}}\left|\begin{array}{ll}a_{0} & a_{2} \\ a_{1} & a_{3}\end{array}\right|=-\frac{1}{0.04534}\left|\begin{array}{cc}0.0002443 & 5.274 \\ 0.04534 & 125.9\end{array}\right|=$

4.5956 (31)

$b_{2}=-\frac{1}{a_{1}}\left|\begin{array}{ll}a_{0} & a_{4} \\ a_{1} & a_{5}\end{array}\right|=-\frac{1}{0.04534}\left|\begin{array}{cc}0.0002443 & 176.6 \\ 45.34 & 0\end{array}\right|=$

176.6

(32)

$c_{1}=-\frac{1}{b_{1}}\left|\begin{array}{ll}a_{1} & a_{3} \\ b_{1} & b_{2}\end{array}\right|=-\frac{1}{4.5956}\left|\begin{array}{cc}0.04534 & 125.9 \\ 4.5956 & 176.6\end{array}\right|=$

124.1577

(33)

$d_{1}=-\frac{1}{c_{1}}\left|\begin{array}{ll}b_{1} & b_{2} \\ c_{1} & c_{2}\end{array}\right|=-\frac{1}{124.1577}\left|\begin{array}{cc}4.5956 & 176.6 \\ 124.1577 & 0\end{array}\right|=$

176.6

(34)

Substituting the values into Equation (29), we have:

$\begin{array}{cccc}s^{4} & 0.0002443 & 5.274 & 176.6 \\ s^{3} & 0.04534 & 125.9 & 0 \\ s^{2} & 4.5956 & 176.6 & 0 \\ s^{1} & 124.1577 & 0 & 0 \\ s^{0} & 176.6 & 0 & 0\end{array}$

(35)

From Equation (35), all the coefficient in the first column have the same algebraic sign (positive) which means that Equation (28) has no root with positive real part or those in the right-half of s-plane. Hence, the conveyor closed-loop transfer function (with controller) is stable.

\section{RESULTS AND DISCUSSION}

\section{A Conveyor System Model with Tuned PID \\ Controller}

The control parameters obtained in figure 11 are: a settling time of 0.835 seconds, the rise time of 0.062 seconds, the percentage overshoot of $4.8 \%$ and no steady-state error. The reduced settling time of 0.835 seconds indicates a faster timing and adaptability of system to additional load. The rise time of 0.062 seconds and small overshoot of $4.8 \%$ further confirm optimization effect of the PID controller on the system. A steady - state error of $0 \%$ shows improved system stability.

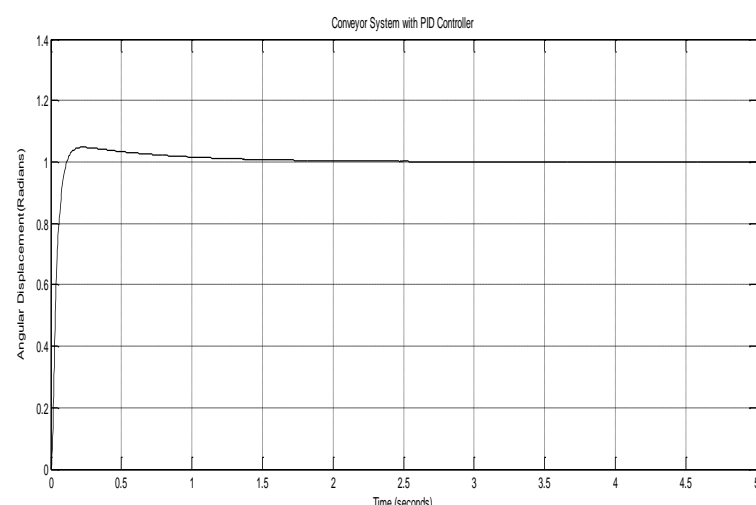

Fig. 11: Step Response of Conveyor Control System with PID Controller.

\section{B Conveyor System Model with Fuzzy-PID}

\section{Controller}

The control parameters obtained in figure 12 below include: a settling time of 0.463 seconds, the rise time of 0.081 seconds, the percentage overshoot of $2.4 \%$ and no steady-state error. The settling time, rise time and percentage overshoot indicates a faster and better tracking performance of the system. This shows the optimization effect of the Fuzzy-PID controller on the conveyor system. The steady-state error which is $0 \%$ shows improved system stability.

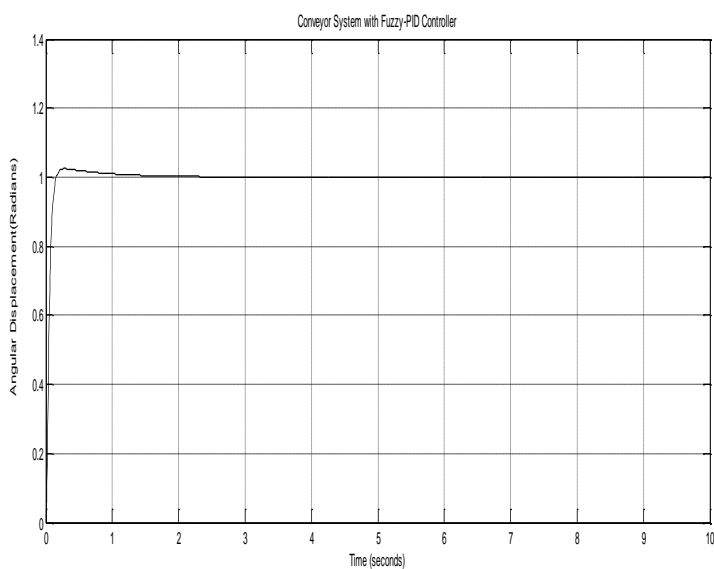

Fig. 12: Unit Step Response of the Conveyor System with Fuzzy-PID Controller.

Table 2: Control parameters of conveyor system with different controllers

\begin{tabular}{|c|l|l|l|}
\hline PARAMETER & PID & FUZZY & FUZZY-PID \\
\hline RISE TIME & 0.062 & 0.235 & 0.081 \\
\hline SETTLING TIME & 0.835 & 0.423 & 0.463 \\
\hline \%OVERSHOOT & 4.8 & 0 & 2.4 \\
\hline
\end{tabular}

As can be seen from the response, PID controller gives the better rise time, whereas Fuzzy-PID controller gives better overshoot and settling time.

\section{CONCLUSION}

The study presented a design of Fuzzy-PID controller for industrial conveyor system. A Fuzzy-PID Controller was designed and integrated with the conveyor system for improved performance. The simulation results of the belt 
conveyor system mathematical model integrated with PID controller, and Fuzzy-PID Controller respectively improved fastness and accuracy in the system response. The simulation results showed that, PID controller integrated with the overall belt conveyor control system gives a better performance compared with previous system. Based on the analysis it was demonstrated that the settling time, percentage overshoot, steady state error and rise time were greatly improved by the Fuzzy-PID belt conveyor control model and controller achieved in this research.

\section{REFERENCES}

[1] D. Gupta. and D. Dave, . " "Study and Performance of Belt Conveyor System with Different Type Parameter". International Journal for Innovative Research in Science and Technology. 2(6), 29-31,. 2015

[2] A.Selezneva. "Modeling and Synthesis of Tracking Control for the Belt Drive System". A Master of Science Thesis, Department of Electrical Engineering Lappeenranta University of Technology, 2(6), 29-31, 2007.

[3] K. Kerkkanen "Dynamic Analysis of Belt-Drives Using the Absolute Nodal Coordinate Formulation", A Doctor of Science Thesis, Department of Electrical Engineering Lappeenranta University of Technology,Lappeeranta, Finland, 2006

[4] G.W. Younkin "Industrial Controls Consulting", Inc. Fond du Lac, Wisconsin, U.S.A., 2(4) pp 36-44, 2003

[5] R..K. Bhoyar . and C.C. Handa, "Design Consideration Of Adjustable Height And Radial Belt conveyor System", International Journal of Engineering Trends and Technology(IJETT)- 4(10),4377-4382, 2013

[6] A. Wahyudie. and T. Kawabe, "' Characterization of all robust pid controllers for belt conveyor system via corrected polynomial stabilization" Research Reports on Information Science and Electrical Engineering of Kyushu University 15, (1),1-6, 2010.

[7] A. J. G. Nuttall. and G. Lodewijks, 'Dynamics of multiple drive belt conveyor systems. Particle and Particle Systems Characterization", retrieved from https://www.researchgate.net/publication/229602109,365-369. DOI:10.1002/ppsc.200601118, 2007.

[8] S.S. Vanamane and K. H. Inamdar, "Design and its Verification of Belt Conveyor System used for Cooling of Mould using Belt Comp Software", International Journal of Applied Research in Mechanical Engineering (IJARME), (1), 48-52, 2011

[9] M. Kasumovi, A., Hodži and M. Tešanovi, . "A Mathematical Model to Choose Optimal Subsynchronous Cascade Elements in Electric-Motor Drives for Belt Conveyors'. Research Gate.7377. 2012

[10] P. M. Deshmukh and S.P. Trikal, "Study, Design Modification And Analysis Of Charging Belt Conveyor System To Set Optimum Results", International Journal of Advanced Technology in Engineering and Science 4(1), 194-202, 2015.

[11] M. A. Umoren, A.O. Essien and I. I. Ekpoudom, I. I. " Design and Implementation of Conveyor Line Speed Synchroniser for Industrial Control Applications", A Case Study of Champion's Breweries PLC , Uyo. Nigerian Journal of Technology 35(3), 618626, 2016.

[12] F. Xing and J. Wauh, "Embedded Intelligent Sensor for Conveyer Belt- Fuzzy System Application", International Journal of Advances in Engineering \& Technology. 1(1), 1-6, 2011.

[13] D.D. Pedersen and H.P. Wolf, ." Conveyor Belt Project. 31340 Computer Control System”, Exercise Journal . pp. 1-12, 2012. 